\title{
LA DELIBERACIÓN EN LA RETÓRICA DE ARISTÓTELES Alberto Buela*
}

RESUMEN: Un repaso sintético de la función de la deliberación en el célebre tratado del Estagirita, cuyo valor radica en recordar los fines y el objeto de dicho concepto, para finalizar con algunos ejemplos bibliográficos en castellano.

PALABRAS CLAVE: deliberación, retórica, Aristóteles, persuasión, felicidad.
ABSTRACT: This article is a synthesis of the role of deliberation in the famous treatise by the Philosopher. Its contribution lies in underlining the purpose and object of such concept. It finishes by providing some bibliographic examples in Spanish.

KEYWORDS: deliberation, rhetoric, Aristotle, persuasion, 


\section{LA DELIBERACIÓN EN LA RETÓRICA DE ARISTÓTELES}

A Quintín Racionero, quien sobre la retórica sabe.

$\mathrm{E}$ s sabido que Aristóteles trata de manera profusa y detenida el tema de la deliberación en libro III de la Ética Nicomaquea, cuando habla acerca de las virtudes intelectuales, a propósito de la téchne=técnica, y allí distingue claramente entre las dos funciones intelectuales que realiza todo hombre: especular y deliberar. Así piensa y filosofa sobre los fines, grandes o pequeños, y delibera sobre los medios.

La especulación, expresada en la investigación filosófica y científica, se ocupa de lo universal y necesario que es lo único sobre lo que puede haber ciencia. Mientras que la deliberación, la estimación, la conjetura y el cálculo versan sobre lo contingente, aquello que puede ser de una u otra manera.
La deliberación se ocupa de aquellos pasos, procedimientos, instrumentos y razonamientos que necesita realizar el hombre a diario para lograr alcanzar la diversidad de fines con la pluralidad de medios que la vida le presenta todos los días.

El otro lugar de su extensa obra en que trata Aristóteles sobre la deliberación es en el libro I capítulos IV, V, VI y VII de la Retórica, cuando estudia el género deliberativo, pero acá a propósito de la persuasión. $\mathrm{Y}$ a esto nos vamos a limitar en este artículo.

Comienza afirmando que no se puede deliberar sobre lo necesario -lo que es o será-, o sino sólo sobre lo contingente, lo que puede ser o no ser, pero no sobre todo lo contingente 
sino sólo sobre lo contingente determinado por las acciones humanas. Es decir, que deliberamos "sobre aquellos asuntos que naturalmente se relacionan con nosotros y cuyo principio de producción está en nuestras manos" (1359 a 37).

De modo tal que la deliberación tiene un terreno circunscrito, por un lado, por lo necesario y, por otro, por lo posible al margen del razonamiento, como puede ser lo que sucede por naturaleza o por azar. La deliberación se mueve y trabaja en el ancho campo que media entre la necesidad y la suerte.

Aclarado qué entiende por deliberación, pasa luego a establecer, siguiendo una vieja tradición que va de Sócrates a Heródoto, los cinco principales asuntos sobre los cuales todos los hombres gustan deliberar, a saber: 1) de la manera de adquirir dinero; 2) sobre la guerra y la paz; 3 ) acerca de la defensa del territorio; 4) de la importación y la exportación; y, 5) sobre la legislación.

Más allá de las consideraciones puntuales de cada asunto se destaca, si lo leemos atenta y varias veces, el hecho de que en tres de ellos (asuntos 1, 2 y 5) se hace mención explícita a "la comparación con lo hecho o sucedido en otros pueblos." Si es en orden a la riqueza, cómo fueron adquiridas por los otros; en orden a las guerras, cómo se resolvieron las de los otros; y respecto a la legislación, conocer las que rigieron a otros pueblos.

Esto lleva a Aristóteles, como muy bien comenta Quintín Racionero, traductor de la Retórica al castellano, a establecer el principio fundamental de las inferencias prácticas, cuando afirma: "pues acontece que de causas análogas se producen resultados semejantes" (1360 a 6). Este principio ya había sido enunciado en la Ética Nicomaquea (1155 a 32) y en la Ética Eudemia (1235 a 5), hablando en esos dos casos de la amistad regida por el principio enunciado por Empédocles de Agrigento: lo semejante llama lo semejante. Esto se encuentra ya en la Odisea: "Como siempre, Dios conduce lo semejante hacia lo semejante". ${ }^{1}$

En cuanto a las inferencias prácticas de cada asunto merecen destacarse las siguientes: para 1) "no sólo se hacen más ricos los que acrecientan sus bienes que ya poseen, sino también los que reducen los gastos" (principio de ahorro); para 2) "hay que saber contra qué naciones podrá hacerse la guerra con éxito, a fin que se tenga paz con las más fuertes y se haga la guerra con las más débiles" (principio de conveniencia); para 3) "saber ubicar las fortalezas para proteger los lugares adecuados" (principio

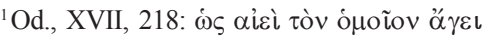

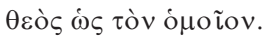


de defensa); para 4) "Es necesario conservar a los ciudadanos libres de todo reproche contra dos clases de pueblos: los más fuertes y los que son útiles para el comercio" (principio antiimperialista); para 5) "es necesario conocer las leyes, ya que en ellas reside la salvaguardia de la ciudad" (principio de seguridad interior).

Es sabido que todo buen gobierno tiene por objetivo el logro del bien común, que no es otra cosa que la felicidad del pueblo y la grandeza de la nación que gobierna. Este buen gobierno se apoya, para ello, en la concordia y prosperidad interior y en la seguridad exterior. La concordia se logra con base en el respeto de las leyes y valores que rigen la comunidad política y la prosperidad, protegiendo la economía ciudadana de los pueblos más útiles para el comercio (ej. Iberoamérica de los ingleses) y reduciendo los gastos públicos superfluos. En tanto que la seguridad exterior, suscribiendo con otros pueblos acuerdos y tratados y sabiendo ubicar las fortalezas para proteger los lugares adecuados.

Como vemos, estas inferencias prácticas realizadas por Aristóteles encierran in nuce un tratado de gobernabilidad, que permite desarrollar lo que hoy se llama ingeniería política.

\section{El fin de la deliberación}

El hombre tiende naturalmente a la felicidad que es el fin último de su acción y por eso siempre que deliberamos sobre algo no podemos dejarla de tener en cuenta. Y como el objeto de la retórica es persuadir, disuadir o convencer: "encontrar en cada caso aquello que puede ser apto para persuadir" (1355 b 25); por ello, el orador debe saber qué es la felicidad, al menos popularmente considerada, y cuáles son sus partes; de esto se va a ocupar Aristóteles en el capítulo V.

No obstante, cabe aclarar que la deliberación está limitada a la contingencia de los medios, en cuanto pueden ser objeto de determinación de las acciones humanas. "Lo contingente es aquello cuya existencia o no existencia depende de nosotros", según Silvestre Mauro (1619-1687), el eximio comentador renacentista de Aristóteles; su vinculación con la felicidad está dada en tanto que ésta es concebida como el fin último del obrar humano. La deliberación ve a la felicidad no como un "fin en sí”, (finis qui), sino como un "fin por el que algo se hace" (finis cui), según la clásica distinción aristotélica.

Así, define la felicidad según el criterio común de pensar de los hombres, afirmando: "entendemos por felicidad el bienestar acompañado de virtud o la independencia económica, 
o la vida placentera unida a la seguridad o el buen estado de la riqueza y de los cuerpos y la posibilidad de conservar y usar de ellos" (1360b 14-17). Y a renglón seguido enumera las partes y los bienes que facilitan la felicidad: la nobleza; los muchos y buenos amigos; las riquezas; los hijos buenos y muchos; la buena vejez; las excelencias propias del cuerpo, como la salud, la belleza, la fuerza, la gran talla y la habilidad para la competición. Y también la fama, el honor, la buena suerte y las virtudes cardinales (prudencia, justicia, fortaleza y templanza).

De modo tal que, quien posea los bienes que están en uno mismo y los que vienen del exterior, podrá bastarse a sí mismo y lograr ser autosuficiente (autárkeia), que es el fundamento de la felicidad.

Veamos algunas de las inferencias prácticas que saca Aristóteles de los bienes que nos pueden llevar al logro de la felicidad: 1) "La nobleza para un pueblo es que sus primeros jefes hayan sido esclarecidos y tenido muchos descendientes ilustres en aquello que es digno de imitación". 2) "Las virtudes de los varones son la moderación y el valor, y en las mujeres la moderación y el amor al trabajo sin mezquindad". 3) "Ser rico consiste más bien en usar los bienes que en poseerlos, pues la riqueza reside en el ejercicio y en el uso de los bienes".
4) "La buena fama consiste en ser tenido como poseedor de algo de tal naturaleza que a él aspiren la mayoría de los buenos y sensatos". 5) "El honor es señal de tener fama de hacer el bien". 6) "La salud es la cualidad del cuerpo que nos mantiene libres de enfermedades". 7) "La belleza es diversa para la edades: la del joven cuerpo útil para el trabajo, las carreras y la fuerza; para el hombre maduro apto para la guerra, y en el anciano ser capaz de soportar los trabajos necesarios sin ser quejoso". 8) "La fuerza es la capacidad de mover otro cuerpo como se quiera". 9) "La buena talla consiste en sobresalir en estatura, volumen y anchura sobre los demás". 10) "La buena vejez es la vejez lenta y sin dolor ni sufrimientos". 11) "Amigo es el que lleva a cabo, por causa de otro, lo que es bueno para ese otro". 12) "La buena suerte consiste en obtener y poseer aquellos bienes cuya causa es la fortuna". 13) "La virtud es la facultad de producir y conservar los bienes y proporciona muchos y grandes servicios de todas clases y en todos los casos" (1366 a 37-39).

El cúmulo de estas enseñanzas prácticas y observables a diario, al ser aprendidas e internalizadas por el orador, lo habilitan para logar el objeto de la deliberación, que es, en definitiva, lo bueno y lo conveniente o útil, tema de los capítulos VI y VII. 
NOTAS

\section{El objeto de la deliberación}

Comienza esta meditación con la tajante afirmación: "no se delibera respecto del fin, sino sobre lo que conduce a obtenerlo, y esto es lo útil y lo bueno respecto de las acciones" (1362 a 17), y realiza luego un catálogo de bienes, para concluir definiendo el bien por su contrario, como "aquello cuyo contrario conviene a los enemigos (1362 b 33) o "aquello por lo que les parece a los hombres digno competir" (1363 a 9). Obsérvese qué lejos está de aquella definición universal de lo bueno de la Ética Nicomaquea (aquello que todos apetecen). Esta caracterización funcional de lo bueno no deja dudas de lo que persigue Aristóteles para la formación del orador: que sea de utilidad privada y pública.

En el capítulo VII establece los grados de lo bueno y de lo útil o conveniente. Trata de aplicar el lugar común-la inferencia práctica-de lo mayor y de lo menor a lo bueno y a lo útil.

Y así, afirma que el mayor bien es aquel que no se sigue de otro. Así, vivir se sigue de vivir bien, y vivir bien no se sigue de vivir, por eso vivir bien es un mayor bien que vivir.

Por la misma razón, es mayor lo que es principio de lo que no lo es y la causa de lo que no es causa. Lo que es fin de lo que no lo es y también lo más escaso, como el oro, que lo abundante. Las cosas que duran más que las que duran menos y la verdad que la opinión. Lo más difícil es superior a lo más fácil como aquello cuyo contrario o privación es mayor. Es mayor lo ostensible de lo que pase inadvertido como lo que elige la mayor parte que aquello que escogen unos pocos.

Los eruditos, aquellos profesores de filosofía que oscurecen las aguas para que parezcan más profundas, al decir de Nietzsche, no se ponen de acuerdo acerca de si los capítulos VI y VII son agregados a complementos del capítulo V; pero el hecho cierto que se desprende de su lectura detenida nos indica que Aristóteles dice las mismas cosas, pero desde distintos ángulos. Así, en el capítulo V la deliberación está vinculada a la felicidad, y en los capítulos VI y VII a lo útil y lo bueno y la jerarquía entre ellos.

Todos estos enunciados y otros más de la Retórica nos muestran que el objeto de deliberación para Aristóteles está concebido más allá de las categorías de necesidad, determinación y cualidad. Lo mayor está pensado como exceso con referencia a una cantidad dada. Responde a la cuestión del sofista Carnéades: ¿Qué es lo último de lo poco y lo primero de lo mucho? Lo primero de lo mucho es aquello que supera el promedio 
medio, y lo último de lo poco es aquello que está por debajo de éste.

$\mathrm{Y}$ termina dando un consejo de un llamativo realismo concreto: "la riqueza y la salud son tenidas por los mayores bienes, puesto que contienen a todos los otros" (1266 b 10-12). ¿Será por eso que Cicerón afirma, en forma contundente, que "en la deliberación el fin es la utilidad y a ésta se refiere todo lo que se relaciona con dar un consejo" (Part., XXIV, 83)?

Así, la Retórica leída desde el punto de vista de la deliberación se transforma en un estudio sobre la lógica de la decisión, donde lo probable lo establece la mayoría o el criterio de los sapientes ( $\varphi \rho o ́ v ı \mu o \varsigma), ~ l o s$ poseedores de la phrónesis, esto es, aquellos hombres que reúnen en sí mismos conocimiento y experiencia.

\section{Nota bene}

De las ediciones contemporáneas en castellano de la Retórica conocemos al menos cinco ediciones: 1) la del investigador argentino E. Ignacio Granero (Editorial Eudeba, Bs.As.1966, pero realizada a partir de 1951 y publicada parcialmente por la Universidad de Cuyo, en Mendoza). 2) La renombrada del filólogo español Antonio Tovar, en versión bilingüe (Editorial Instituto de Estudio Políticos de Madrid, 1953). 3) La del traductor popular de Aristóteles, Francisco P. Samaranch (Editorial Aguilar, Madrid-Bs.As., 1967). 4) La del filósofo español Quintín Racionero, con una excelente introducción de 152 páginas (Editorial Gredos, Madrid, 1990). Y finalmente, 5) la del también filólogo español Alberto Bernabé Pajares (Editorial Alianza, Madrid, 1998).*

* Conviene mencionar también la excelente edición bilingüe de la UNAM: Aristóteles, Retórica, México, UNAM, Bibliotheca Scriptorum Graecorum et Romanorum Mexicana, 2002, introd., trad. y notas de Arturo Ramírez Trejo, CCCIV+187 pp. (N. del E.). 
CITAM Derechos Reservados.

La reproducción total o parcial de este artículo se podrá hacer si el ITAM otorga la autorización previamente por escrito. 